\title{
Epistemology of Optimization Models for Decision Making in Organizations
}

\author{
Augusto Renato Pérez Mayo (Corresponding author) \\ $\mathrm{PhD}$, Faculty of Accounting, Administration and Informatics \\ Autonomous University of the State of Morelos, Cuernavaca, Morelos, Mexico
}

ORCID: 0000-0003-1094-3283

E-mail: renatomayo@ hotmail.com

Nohemí Roque Nieto

PhD Candidate, Institute of Education Sciences, (IES)

Autonomous University of the State of Morelos, Cuernavaca, Morelos, Mexico

ORCID: 0000-0002-3546-0213

Daniela Beatriz Salgado Arteaga

Student of the Specialty in Human Resource Management

Autonomous University of the State of Morelos, Cuernavaca, Morelos, Mexico

Received: July 13, 2017 Accepted: July 27, 2017 Online published: August 4, 2017

doi:10.5296/ijhrs.v7i3.11644 URL: https://doi.org/10.5296/ijhrs.v7i3.11644

\begin{abstract}
The intelligibility nucleus that subjects use for decision making in companies such as models based on nomothetic sciences and ideographic sciences has been applied to a wide range of situations within different areas of management. In the conscious decision making under certainty or uncertainty, limited or unlimited rationalities, every day or complexities and static or emerging properties, analyzes, forecasts, predictions and interventions are always performed. We might think that we are not forecasting, but our options will be driven by the anticipation of results of actions or inactions. The application of Optimization Models for decision making has in each moment an epistemological support, in the thinking and acting in the organization; therefore, have also served to analyze the organizations at their different
\end{abstract}


levels. All this is argued in epistemological cradles that define the direction of organizations.

Keywords: Epistemology, Organization, Optimization, Methods and Decisions.

\section{Introduction}

In everyday life an individual often faces many optimization problems. For example, choose if to reach your work center uses public transport or taxi to distribute your expenses; when you have unexpected visits at home and when you open the refrigerator decides what to prepare. Obviously, in none of these cases does this individual use formalized and rigorous mathematics, as in the formal exercise of decision-making, to achieve an objective or goal within an organization. Beyond the everyday, in the world of organizations the problems that must be resolved in time and form. Without a doubt, in many cases a solution to a problem can be considered optimal, exceeding the criteria of choice provided by the experience and intuition of the subject. It is here that the need to understand the utility of alternative methods for selection in such specific aspects as decision making, operations research or optimum topologies for the analysis of organizations is highlighted.

The present article seeks to examine, through a new look, the epistemic cradles of the Optimization Methods, their parsimony, plausibility and probability of application. The tendency to complexity and mathematical sophistication of decision-making, based on probability, points out that educational requirements need to approach knowledge in philosophy of science, theory and statistical methods in the light of some methodological coherence. This interpretive turn will be necessary to understand the operation of the various methods available, but above all, to visualize its theoretical bases and critically complement which of the options will be possible to use it in the different phases of decision making.

This paper is divided into four sections. The first addresses the problem of knowledge in organizations. He realizes the two traditions in the history of the philosophy of science that establish deep differences regarding the conception of science: Aristotelian and Galilean as explanations of the world. The second part discusses the epistemic bases of the construction of knowledge. In a third moment the connections between the epistemology and the optimization models are considered. Finally some reflections are proposed by way of conclusion.

\section{The Problem of Knowing in Organizations}

Efforts to understand the internal and external dynamics of organizations have highlighted the need to return to approaches around knowledge. Individuals In modernity have tried to deepen and philosophically ground human knowledge on ways to optimize their decisions. Human knowledge, undoubtedly, is not limited to the phenomenal scientific world, it disrupts various spheres: metaphysical, philosophical and religious, these visions that have sought historically are to interpret the sense of self in front of its surroundings. Hessen recalls, through six problems, how the knowledge of individuals has been constructed (Hessen, Gaos and Romero 1970). From its origin, essence, forms and possibilities are related to a criterion of truth and knowledge base for decision making. It becomes a problem because the 
availability and the sense of time to construct that knowledge are very different in their productive distribution as of the resources of the individual. Knowledge in organizations has a faster pace given the conditions imposed by the modernization processes where the use of technologies and efficiency are used for their use.

In this sense Villoro offers a systematic analysis of the fundamental epistemic concepts with which the actors and organizations build their knowledge and make their decisions. Establishing relationships with the reasons that justify the truth of the beliefs of individuals and with the motives that can distort them. That is, the most important dilemmas arise from the ontological and epistemological point of view of knowing. For the analysis of the organizations, the search for new logics of knowledge is related to the construction of novel conceptual instruments. Its applications involve continually approaching them through new areas of analysis to face the demands of new problems that originate the optimization in its broadest conception.

Some theorists like Gergen (1996) ask questions about the relationship between knowledge and its application. For example, when one questions how individuals know and decide a possible answer could be directed to show a new logic of knowing. A model that houses as core of intelligibility the "theory continues." Understood as a set of assumptions that are not located in explicit theory, rather, beyond pre-established theory. This combination between what is given and what is assumed determines a practical form of knowing, turning it into a methodology for organizational knowledge and its models of decision making.

Undoubtedly, in order to know and decide, it is first necessary to clarify its concepts and methodology. This exercise seeks to be cautious in the treatment of theoretical concepts and the design of a theory of knowledge in organizations. In this regard, Nonaka and Takeuchi (1999) highlight a reason, from their Eastern vision, that a large part of Westerners tend not to talk about the creation of knowledge in organizations. It is assumed that they are "information processing" machines where all the individuals involved unify a mass of knowledge. This point of view refers to recognizing that knowledge is formal and systematic to be explicit within the organization. Toffler (1990) uses as synonyms the words data, information and knowledge, to avoid tedious repetition.

According to Nonaka and Takeuchi (1999), Japanese companies have a very different idea of what it is to generate knowledge and optimize through it. The one expressed in words and numbers with the ability to be transmitted and easily shared in the form of data, scientific formulas, codified procedures or universal principles is explicit knowledge. In the Japanese business world, tacit knowledge, hidden and difficult to express, is more valued. The origins of this knowledge are very profound, as it is derived from individual actions and experience, acquiring form in ideals, values and emotions. In the field of organizations, it is expressed in skills known with the jargon Know-how "know-how", since they include schemas, mental models, and shared beliefs collectively. The authors already mentioned, recognize that tacit knowledge can be divided into two dimensions: technical and cognitive although they cannot be enunciated easily, these implicit models control the way individuals perceive and optimize in the world. 
In this respect Polanyi marks the difference between explicit and tacit knowledge, the latter is the key to understanding the differences in which the East and West deal with knowledge. The explicit, by its objective nature would be processed by a computer, transmitted electronically or stored in databases. While the subjective and intuitive nature of the tacit makes it difficult to process or transmit it systematically or logically. For this knowledge to be transmitted and disseminated among the members of an organization, it must be converted into words or numbers in the public domain.

This is why Polanyi delineates tacit knowledge as part of cultural habits and aspects, which the individual hardly recognizes in himself. Herein lays the importance for knowledge management, when reference is made to knowledge that only the individual knows and that is difficult to explain to another person. Therefore, tacit knowledge is valid for solving a problem, to pursue and guide its sense of approaching its solution. In short, tacit knowledge allows us to understand and explain the emergencies originated within an organization, its complement, the explicit is superficial and exploratory. However, as Krogh, Ichijo and Nonaka (2000) put it; tacit knowledge for value requires making it explicit. For the above, we discuss the concept of organizational learning analyzed in different modalities by different theorists.

Argyris (Ichijo, Krogh and Nonaka 2000) refers organizational learning to the detection and correction of error, as Fiol and Lyles (Ichijo, Krogh and Nonaka 2000) as the process of improving actions with a better knowledge and understanding, Dodgson (Ichijo, Krogh and Nonaka 2000) as the way companies construct, provide and organize knowledge and routines around their activities and within their cultures; Adapting, developing organizational efficiency by optimizing the use of the broad skills of their human resource, Huber (Ichijo, Krogh and Nonaka 2000) understands it as the optimizing process through information, for the range of their potential behaviors.

Each of these authors agrees on the optimizing proposal, since behind an optimizing mental exercise, it is possible to identify a philosophy of science and a theory of society (Burrel and Morgan 2006). For these theorists, thinking is an instrument that results from a synapse prolonging the neuronal life that allows the constitution of a nervous system that determines the way of knowing individuals, and therefore the optimization of their behavior in organizations. (Maturana and Varela 1990). A great majority of the optimization models fail to penetrate, by their "explicit" rational nature, the epistemic base.

\section{The Epistemological Basis}

Burrell and Morgan (2006: 311-325), in their book Sociological Paradigms and Organizational Analysis argue that all theories of the organization are based on a great theory of the society composed by philosophy of the science, that is to say, an ontology, Epistemology and methodology. There are two traditions in the history of the philosophy of science that establish deep differences regarding the conception of science: the Aristotelian and the Galilean. As explanations of the world, the teleological or finalist contrasts with the causal or mechanistic. Aristotle's theory of science is based on teleological explanations, which make it possible to clarify "with what purpose" phenomena occurred, whether related 
to the growth or development of living organisms, or inorganic beings or inanimate objects (Oriol Anguera and Espinosa Hernández 1994). This episteme tries to penetrate in the things to explain them, tries to replace them by more precise ones. The union between science and philosophy, typical of Greece, cracking in the modern and contemporary world. With the new Galilean epistemology, science begins to move in the realm of the positive.

The Galilean explanation holds that nature is not explained in terms of the future, but of the past, giving rise to the causal explanation. It conceives of scientific explanation as a fact, one that is formulated in terms of laws that relate phenomena determined by mathematics. Such explanations will take the form of causal hypotheses, but causal will have here a functional connotation in a mechanistic perspective. Finally, the touchstone of the value of our causalist assumptions will be determined by experimental analysis. It will be the comparison of the hypothesis with the consequences deduced by observation of reality or experimentation which will give us its explanatory value.

Positivism, heir to the Galilean tradition, which reached its maximum expression in the nineteenth century positivist scientism, giving rise to positions that reformulate and introduce new terms and ways to reach scientific knowledge. It is evident the positivist position and its integrated scientific method called logical-deductive. Burell's own intention says it all: it is about explaining and predicting what happens in the social world by searching for regularities and causal relationships between its constituent elements, with the methodology of the empirical sciences, the various aspects of organizational reality, In order to explain it as far as possible.

The common opinion on scientific knowledge is no longer valid in contemporary epistemology. The thesis that scientific knowledge is reliable because it can be demonstrated objectively has entered into crisis. Scientifics reductionism falters. Concepts such as: conjectures, falsification, criticism, hypothesis, intersubjectivity, innovation, change, acquired great significance before these others: verification, certainty, objectivity, tradition, stability. Names such as Popper, Feyerabend, Lakatos, Kuhn, among others, arise in the scientific horizon to delimit the boundaries between scientific and non-scientific and to specify in new terms, what should be called science. Following this argumentative idea, let's see how one begins to construct the knowledge where the individuals transit through organizations with different institutional logics.

Empiricism conceived as a philosophical movement has multiple ramifications. The only feature common to all multiple ramifications is to admit only one medium of knowledge: experience. Accurate recording of sensitive phenomena, facts based on experience, are essential tasks for the followers of these approaches. All abstraction is linked, according to this position, to concrete objects of knowledge. Plato: points out that the sensible world is knowable through experience insofar as the intelligible world is knowable through reason. The Aristotelian theory indicates that the experience starts from sensations that generate memories.

Tomas de Aquino recognizes two sources of knowledge: the senses and the understanding. Its fundamental postulate indicates that all knowledge is born of experience; therefore, all 
sensible knowledge precedes the intelligible. Thus we see that "understanding can only produce concepts with the data that the senses provide" (Garcia 1991: 107). The direct antecedents of the English "classic" empiricism of the seventeenth and eighteenth centuries reveal a pragmatic tradition of English versus continental culture "devoted to the great speculative problems" (García 1991: 170) found in the statements of Rogerio Bacon, Ockam and Francis Bacon throughout the thirteenth, fifteenth and sixteenth centuries.

Bacon points out that experience is the apprehension of singular things and also accepts it as a result of inner enlightenment. It raises two of the theses that become the maximum frontier levels in scientific thought: empirical verification (of what the experience through mathematical models) and the technical control of research. Francis Bacon (Garcia 1991: 107) conceives experimentation as ordered experience. The philosopher-bee "who collects and orders the above" will be imposed, in the opinion of this thinker, on the spider-philosopher whose speculative task generates products that do not interest. Fertile inductivism will be imposed on sterile deductivism; the greatest demonstration is experience; Of course, provided he does not go beyond the experiment itself. "Paradoxically, this inductivist author rejects the use of mathematics because he considers it speculative and unnecessary to speak of the laws of nature. Mathematics will become for other inductivists the cornerstone of scientific demonstration.

For Ockham, the most radical separation between faith, reason, and empirical knowledge is presented. In the opinion of this author, neither the existence of the soul nor the existence of God is demonstrable since the basis of reason and scientific knowledge is experience. Ockham adopts a nominalist or conceptualist attitude. Observation and experience become a criterion of truth. It is only possible to know the singular objects produced by sensible experience and those realities whose existence is necessarily inferred from intuitive knowledge (Kolakowski and Ruiz-Ramón 1979: 19).

The main exponents of English empiricism are: Locke, Berkeley and Hume. For Locke all knowledge comes from experience. The mind is a blank paper that is filled with ideas from experience. The idealist Berkeley is included within the empiricists by virtue of which he identifies ideas with reality. Ideas are things perceived. The most radical of empiricists Hume who conceives of knowledge formed by impressions or ideas. The first are sensitive, the second, copies of the impressions. According to Hume knowledge only reaches phenomena and therefore metaphysics is impossible. It is clear the use of experience as an optimization model of intuitive reflection of the actors in organizational life.

\section{Rationalism in Hindsight}

One of the main questions to the various empiricist positions points out that the subject for empiricism becomes a liability whose fundamental task is to receive and process impressions derived from sensible experience. In this way man is deprived of intelligence and reason. The rationalist position tells us that reason is capable of leading us to the truth. Only she is able to organize "the gross sensitive data of the sensibility". Sensitive experience only brings knowledge of particular cases "never a general truth". One of the aspects generally attributed 
to science is its legal character. This character is given the reason. "Science consists of necessary and universal judgments, since it is not limited to examining the facts, but rather it enunciates laws." Intelligence allows man to formulate abstract and universal concepts and categories. Thus, it is assumed that intelligence is the management of concepts, not empirical data. The foundation of knowledge in this sense "is not sensitive, but intellectual".

The merit of rationalism consists in having seen and emphatically stressed the significance of the irrational factor in human knowledge. Rationalism raises the unique validity of knowledge based on reason. Only knowledge based on reason is valid, because only then can science be made up of universal and necessary judgments. The main representatives are: Parmenides, Plato, Descartes, Malebranche, Spinoza and Leibnitz.

Plato is rationalist because the senses only provide opinions. Universal and necessary knowledge is of an intellectual type; Certainty is only acquired when intelligence intuits ideas. Man has his own innate ideas, but the body is guilty of forgetting such ideas. Little by little he remembers them. "Learning is remembering." Descartes aims to eliminate doubts of skepticism in a rational, scientific and rigorous way. Just as he fails from the moment he tries, in the mathematical way, to prove everything from his own ideas; the intellectual evidence becomes a criterion of truth. From Descartes the following problem arises if what we know are ideas ...? How can we know that these correspond directly to reality?

For Spinoza, reality contains a formal or logical structure. Consequently, the human mind must start from clear and distinct ideas to draw the necessary conclusions from them. The order of ideas must have an exact correspondence with the order of things. In such a way, reason alone, without the aid of experience, is capable of grasping the structure of reality. According to Leibnitz there are truths of reason, which are absolutely necessary and its opposite is impossible because of absurdity, and truths of fact, which are contingent and its opposite possible. According to rationalism, true knowledge does not come from experience but from reason, so that it is only possible to accept those propositions "certain and evident for reason." The intellectual evidence is placed above the empiria, as a criterion of truth. "Reason alone, without the aid of experience, is capable of grasping the structure of reality." According to Leibnitz, "truths of reason are absolutely necessary and its opposite is impossible because of absurdity ...". (Mardones 1991)

In short, rationalism raises reason as the only source of true knowledge and rational evidence as the basis of scientific knowledge. The questioning of rationalism indicates that this is exclusive, denying the path of experiential knowledge; also questioned that rationalism cannot be justified without coming to experience.

\section{The Antipositivism}

Mardones and Ursua (Mardones 1991: 149), suggest the existence of two important philosophical currents and have served as a basis for understanding and optimizing the everyday and organizational world, which have in common the resolute opposition to positivism and its claim to consider scientific Only the explanations that incline to the model of the natural sciences and, in particular, of the physical-mathematical one. Such postures are 
hermeneutic and linguistic phenomenology and the dialectical or critical hermeneutic posture.

Dilthey, Ranke, Windelband, Rickert and Weber are enrolled in the first stream. Given the identity between subject and object, understanding turns out to be "the appropriate method to capture a meaningful, intentional mode" (Mardones 1991). Linguistic mediation is a way of approaching human intersubjectivity. The understanding of everyday life is linked to communicative interaction and common language. There is a non-explicit pre-intelligence that cannot be explained in an empirical-analytical way and also allows organizations to study and intervene; In addition, there are some previous ones accepted by the researchers, regarding the social norms and the same process of investigation that can only demonstrate phenomenologically and hermeneutically. Zones and sources of reason, in short, that are not reducible to empirical analysis (Mardones 1991: 150)

The Weberian claim to understand and interpret the meaning of social action to be able to explain it in its development and defects is located in a perspective of qualitative sociological analysis. The dialectical or critical-hermeneutic posture recovers the critical tradition of Marxism; its exponents are most of the members of the school Frankfort, Korsh, Lukacs, Habermas and Apel. Some of the basic assumptions taken up by this position are the character and the need to situate the facts in a social whole so that it makes sense; the interaction between subject and object of knowledge. Habermas places the dialogue in a central position of the scientific work. The possibilities of thought are derived from a language eminently social and impersonal. According to these assumptions, analysis of communicative action becomes relevant.

\section{The Quantitative and Qualitative Paradigms in the Studies of the Organization. Optimization Models and Organizational Phenomena}

The Belgian Adolphe Quetelet is one of the pioneers in the application of statistical methods for the analysis of social systems such as population growth. From a positivist orientation Quetelet aspires to create a social science based on the model of the physical-mathematical sciences. The creators of the new social science claim that both the method to be used by sociology and the attitude towards its object of study are similar to those used by scientists whose object of study are the phenomena of nature. As a result of the above, the use of induction, data collection and ahistorical comparison of the same ones becomes a priority "... the association between the Biological and Social Sciences made them acquire some habits of observation and used partially The inductive logic thus breaking, to a certain extent, the habit of using deductive arguments from the first principles they had inherited from Aristotle... "(Bernal 1997: 289).

The type of explanation which, according to positivism, the social sciences need to offer, must be based on arguments of a physical-mathematical nature (Mardones 1991: 152). These approaches are exposed from various approaches by authors such as the classics of positivism (Comte, Stuart Mill) and more recently by Neopositivism. In the field of statistical correlation of variables, Durkheim achieves a great advance. Some of the data collected regarding suicide are processed according to the progress of statistical techniques of their time. However, the information it presents regarding this phenomenon is susceptible of analysis 
through more advanced techniques. Durkheim is one of the social scientists who puts more emphasis in the study of the social facts "as things" and in the approach of these from the data. That is, the empirical search for information optimization.

Taking the quantitative position to extremes limits would exist the possibility that the researcher in social sciences would arrive, through the use of mathematics, to establish laws, principles, categories and postulates applicable to any context. In this case, the extensionalist language of mathematics would be extremely useful. One of the fundamental assumptions of this current is that the expert in social and administrative sciences works with data and that, with these data, it is not only possible but necessary, to analyze them logically and through the use of mathematical models. If this is not so, then some authors such as Martindale (Wilson and Giddens 1990) tell us, one would be abandoning the field of science to enter the speculative field of poets, myth-makers, ideologists and politicians. Therefore, the meaning of organizational life for Martindale must be something that can in principle be apprehended by standard logic, mathematical models, otherwise it is beyond the scope of rational inquiry.

\section{The factors of Quantitative Analysis}

The quantitative analysis aims to count or enumerate the objects of study (their aspects) and verify the regularity with which a phenomenon occurs. This type of analysis also allows us to compare the objects of study be these individuals, groups, institutions or societies. The translation of social phenomena into figures and symbols makes possible their technical manipulation.

"... quantitative analysis ranges from the simplest procedures of elementary mathematics to the more complex procedures of probability theory and mathematical statistics" (Luengo-González 1991).

Two of the central aspects of the quantitative paradigm are number and measure. From a quantitative approach, propositional language expressible in a logical form is common. The quantitative methods are based on a theory of hypothetical, deductive nature, which is part of the design of the hypotheses to be contrasted. To this starting point is followed the application of the inductive analytical procedure that seeks to investigate whether "two variables are functionally related under conditions of rigorous control". In general, this procedure consists of provoking or observing changes in a (independent) variable and recording the possible alterations or lack of them in another (dependent) variable while keeping other involved variables in check.

In order to achieve greater objectivity and / or reliability of the studies that are carried out, those who opt for quantitative methods make use of techniques and instruments that are wanted outside, independent or external to those who investigate. The design of quantitative research is about having pre-structured designs in which the entire process is contained. The criterion of fundamental quality of the quantitative methods is the rigor, expressed in methodological terms of external validity. In these methods, based on the control and manipulation of variables, it is played with the levels of internal validity, safety in the result obtained, and external validity, possibility of generalizing the obtained results. That is, 
sometimes the studies performed have a great internal validity but little external validity, when there is no control or when the study is developed in an artificial environment. However, the opposite may also occur, to reduce internal validity in order to improve external validity. The latter occurs in the case of quasi-experimentation and ex-post-facto studies.

Another perspective based on which quantitative studies are addressed, is that of explanatory power. In this case the internal-external validity of the results pass to second place and special attention is given to the model that allows us to explain and predict the behavior of the phenomena studied, developed from the research process. According to Cook and Reichardt (1986a), the quantitative approach presents, among others, the following characteristics: measurement provoked and controlled for objective verification; Of confirmatory, inferential and hypothetical-deductive studies oriented to repeatable and generalizable results; Use of experimental, particularistic, analytical and reductionist methods that represent a stable reality; Development of surveys through which the measurement of indicators and the verification of theory are sought.

Among the quantitative methods of more general use are: "all modalities of correlational analysis, both bivariate and multivariate: regression and partial and semi partial correlation, causal analysis, factorial analysis (across its range of methodological alternatives), Discriminant analysis, canonical analysis, cluster analysis, correspondence analysis, latent structure analysis; The longitudinal and transverse methods, with all their variants and modalities, which are basically used in evolutionary and differential studies.

\section{The Emergence of the Qualitative Paradigm}

Given the presence of vague and imprecise phenomena (Moles, Rohmer and Covarrubias 1995), the forms of study based on empirical proposals are insufficient. The alternative for the study of this permanently variable reality, on the basis of which we think and act, constitutes the qualitative perspective. The qualitative style of epistolary and biographical character has its climax. They stand out in techniques such as interview, participant observation and Life stories "Globally the works stand out because of their lack of representativeness, verification of hypotheses and statistical analysis, as well as the inherent subjectivity of their interpretive flexibility." (Oriol Anguera and Espinosa Hernández 1994). Between the thirties and the sixties, the decline of the qualitative methodology in favor of the quantitative methodology is observed. Thus, the insufficiency of qualitative studies for the verification of hypotheses and for statistical analysis is posed. The usefulness conferred to the studies of a qualitative nature corresponds to the exploratory phases.

It is, at the end of the sixties, when a qualitative paradigm emerges that is expressed through the revaluation of the role that theory plays in the role of research. In this recovery, the development of various procedures for the treatment of qualitative data also plays a prominent role. Cook and Reichardt consider that the qualitative paradigm is nourished among others of the following elements (1986a):

- Comprehensive analysis. It seeks to understand the intention of the actors from the perspective of their own frame of reference. 
- Subjectivity. Positions that emphasize the inner analysis or introspection of human behavior are taken up again.

- Case studies, not generalizable, descriptive, expansionist and inductive, assuming a dynamic reality seek depth in the data.

- Development of methods based on the observation and strengthening of perspectives such as ethnomethodology.

The qualitative paradigm conceives the existence of multiple realities that the researcher constructs and determines. One of the basic tasks of qualitative research is the search and description of key incidents in a broad context. These kinds of incidents demonstrate the functioning "of abstract principles of social organization" (Cook, Reichardt and Solana 1986b: $64)$.

The recording of the observations is carried out mainly through the language of the subjects, since this is basic in the knowledge of the significant systems of the participants. The fact that the theory, concepts and categories arise from the information that is collected, from the perspectives of the participants, enhances the capacity of understanding and explanation on the part of the researcher. Unlike the quantitative paradigm the qualitative is based on the open model in which the theory does not determine, but is determined, is not checked but discovered.

Two of the schools that develop and strengthen qualitative methods of approaching social reality from interpretive sociology are symbolic interactionism and ethnomethodology (Giddens 1987). In the face of the proposals of behaviorist reductionism and structural determinism, symbolic interactionism seeks to find in social interaction the modeling of the capacity for thought. In this interaction, the meanings and symbols used are modified or altered. The rejection of conventional techniques of predominant quantitative study, the sympathetic introspection posed by the need to put oneself in the place of the actor, the use of intuition is part of the contributions and weaknesses that, from a qualitative perspective, has developed the interactionism symbolic. Ethnomethodology focuses on intersubjectivity. The intersubjective world or everyday life is what creates social reality. The unveiling of practices, through which people live their daily lives, is carried out fundamentally through the study of institutions and conversational analysis.

\section{The Prospects for Quantitative-qualitative Integration}

The debate between qualitative and quantitative methods starts from the assumption of considering both as excluding, The supporters of each of them raise the superiority of their perspective of approach. Qualitative and quantitative methods as a paradigm, guide the work of various disciplines and the resolution of the problems they face, indicate criteria for the use of methods, techniques and instruments and establish principles of epistemological order from which work is organized Research.

No paradigm has a monopoly on correct answers. The possibility of collecting multiple perspectives of the object of study from the use of different methods allows a greater wealth 
in the processes and results of the investigation. The achievement of similar results through various means, through triangulation procedures, gives greater reliability and validity to the observations around what is investigated. Triangulation allows "the deficiencies of one method to be compensated for by the strengths of other methods" (Denzin 1973).

The empirical world unveiled by statistical relations, is linked to the world of life that, approached from a qualitative perspective, allows to understand the meanings of social action. "A better balance is required between the everyday basis of meanings in social action and the generability of such meanings to a wider context. This is the challenge of qualitative and quantitative methods to describe the world and its decisions ... "(Cook, Reichardt and Solana 1986: 76).

Grawitz (1984: 321) argues that "... most social science researchers admit that there is no one technique, only one means that can be used in all social sciences. They recognize that there is no opposition between qualitative and quantitative, but a continuum that does not go from systematized qualitative research to the most rigorous forms of measurement. The increasingly close link between the qualitative and the quantitative allows us to assume that "both perspectives are necessary and that they can function together and complement each other" (Oriol Anguera and Espinosa Hernández 1994: 28). Thus, recent trends are advancing in the sense of integrating paradigms that at the time were presented as exclusive to achieve the combination that is more appropriate to the problem of research and the environment in which it is.

The mixture of attributes of both paradigms reports potential advantages such as: multiple targeting, greater depth of studies for optimization models to be more objective and the possibility of triangulation of information and, by that way, correcting some of the Biases present in the approach from a single paradigm. The combination must be such that the techniques and instruments coming from both of them complement each other as part of a strategy in which heuristics play an essential role. The application of qualitative methods can serve as antecedent complement or confirmation of the application of quantitative methods. This situation may also arise in the opposite direction. In both cases we find a mutual benefit and a greater level of depth and reliability in the analysis. Only as an example, the generalization of findings found at the micro sociological level can be carried out through quantitative methods. On the other hand, the qualitative studies can grant a greater level of reliability and depth in the sociological analysis of quantitative cut.

\section{The Challenges of Quantitative-qualitative Integration}

Cook and Richardt (1986a) show us the limitations of the basically quantitative perspectives conceived in unilineal terms. They point out to us that the polarity with which they are usually presented is false, since, for example, quantitative scholars are charged with a great deal of subjectivity. They point out to us that the situation is what ultimately determines the method or methods to be used. Emphasize, the problem of quantitative-qualitative integration, as planned by these authors, remains unresolved. The question is not what paradigms to integrate or why to integrate them. The bottom line is how and why to integrate paradigms. The issue of the combination of paradigms is present both in the formulation of objectives 
and in the design of research and the scope and resources it may have.

One of the cornerstones of this problem lies in the researcher's ability to combine the advantages of both approaches. The breadth of the options offered by both the quantitative and qualitative perspectives requires a training that allows them to recognize their scope and limitations in approaching a concrete phenomenon of social reality. The approach of the objects of study from a comprehensive approach can hardly be carried out in an improvised way. This situation forces to rethink the formative processes of the researchers. The various models of research to optimize configure a menu, to which the researcher can go to return to the proposals required by the object of study, as well as the depth and rigor with which he intends to approach it. The limitation in this sense derives fundamentally from two factors; the nature of the problem and the degree of creativity and ingenuity of those who carry out the research design to optimize.

Some operational obstacles to the joint use of quantitative and qualitative methods are the high cost, the longer time, the lack of training for the joint use of both methods, and the omnipresent fads in the research processes often assumed by the Funding bodies. Another aspect that can be more problematic when quantitative and qualitative paradigms are integrated is quantification without impoverishing the most interesting qualitative elements (Grawitz 1984: 324).

Blends lead to another problem no less complex, how and why to carry them out? This question allows us to the criteria on the basis of which the paradigms will have to be integrated. The pragmatic approach can be risky and lead to false solutions, which, far from helping, can make the research process more complex. Another prevailing knot is the reconciliation of perspectives that, from the ontological and epistemological point of view, still remain irreconcilable, at least from the ideological point of view.

\section{Optimization Models}

As mentioned at the beginning of this article, in everyday life we are often facing many optimization problems. Obviously, in none of these cases do we use formalized and rigorous mathematics to find what we are proposing, because we face problems with the criteria that give us experience and intuition, although we do not necessarily find the optimal solution, this reflection is the one made in paragraphs Previous, optimization with intuitive reflection based on experience.

However, in a broader perspective, we see that optimization problems are a fundamental part of mathematics and were already present in the treatises of the Greeks of antiquity. A sample of this is the book $\mathrm{V}$ of the work on conics written in eight volumes by Apollonius considered one of the most important Greeks of antiquity, who lived between the years 262 and 190 BC. - in which it is dedicated to study segments of maximum length and minimum length drawn with respect to a conic. Certainly, a historical milestone is marked by the development of differential calculus in the seventeenth century and the use of derivatives to solve problems of highs and lows, which further extended the applications of mathematics in various fields of science and Technology and thanks, above all, to Euler who proposes and 
creates the calculation of variations, considering the obtaining of functions that optimize functional, which provided valuable mathematical tools to tackle more advanced problems.

According to Boyer (1997), Apolonio argues in his introduction, that "the subject is of those who seem to be worthy of being studied for their own interest". Kline (1990), says: Apolonium "shows that if $\mathrm{O}$ is any point inside a conic and if $\mathrm{OP}$ is the line segment of maximum or minimum length from point $\mathrm{O}$ to conic, then the line perpendicular to OP In $\mathrm{P}$ is tangent to the conic in $\mathrm{P}$; And if $\mathrm{O}$ 'is any point on OP produced outside the conic, then $\mathrm{O}^{\prime} \mathrm{P}$ is the minimum length segment from $\mathrm{O}^{\prime}$ to conic. Now this property is pronounced as the perpendicularity between the tangent and the normal. " This problem can now be seen in a more general context, as part of the study of the conditions of transversality in problems of calculation of variations, which is a theory created by Euler in the eighteenth century, which optimizes a functional and optimizing object Is a function. It is pertinent to take Boyer's (1997) statement about the work of Apollonius:

"At the same time that one cannot fail to admire the author for his elevated intellectual
attitude, it seems appropriate to note that what was once simply a beautiful theory, with
no possibility at all to be applied to science or technology Of the time, has become a
fundamental theoretical instrument in fields such as terrestrial dynamics or celestial
mechanics. The theorems of Apollonius on maxima and minima are actually theorems
about tangents and normal to conic sections. [...] It is therefore quite clear, in other words,
that it was the pure mathematics of Apollonius that made possible the appearance some
1800 years later of Newton's Principia ...

The following is another paragraph from Boyer's book, which refers to a historical fact of antiquity linked to optimization problems and reminds us of one of Aristotle's philosophical principles, which attributes to nature an optimizing behavior (1997):

"Heron seems to have been the first to demonstrate by simple geometrical reasoning in a work on Catropic or study of reflection that the equality of angles of incidence and reflection is a simple consequence of Aristotle's philosophical principle that Nature always proceeds in the simplest or "economic" way. That is to say, if a beam of light rays starts from an S-beam, it is reflected in a mirror MM 'and then goes to the eye $\mathrm{E}$ of an observer, then the light must travel the shortest possible path SPE, which is exactly that in which the SPM and EPM 'angles are equal".

Another important milestone in the history of optimization is marked in the first half of the twentieth century when developing linear programming. Kantorovich and Koopmans received the Nobel Prize of economy in 1975, in recognition of their contributions to the theory of optimal allocation of resources, with the mathematical theory of linear programming. In this brief historical look, it is important to mention that Fermat (1601-1665), before Newton and Leibinitz published their works on differential calculus, invented ingenious methods to obtain maximum and minimum values; That Jean Baptiste-Joseph Fourier (1768-1830) showed intuitive approaches to optimization methods currently considered in linear programming; And that the rigorous treatment of the ideas of Newton and Leibinitz - and of many others prior to them, which brought relevant ideas to 
mathematical analysis - was only developed in the nineteenth century with Cauchy, Weierstrass and Dedekind. Thus, in the history of mathematics - and in particular in subjects related to optimization - we have shown the close relationship between intuition and rigor and have led leading figures in mathematics to take a stand on this subject. Suffice it to mention Félix Klein (Germany, 1849-1925), a leading geometer, author of the famous Erlangen program, who stated that "In a certain sense, mathematics has made more progress thanks to people who have distinguished themselves by intuition, not by The rigorous methods of demonstration "(Perero 1994: 101) and L.

Another interesting historical fact that makes us see how the ideas of maximum were present in a correct perspective, although not necessarily rigorous and formal, is the work of Pappus of Alexandria, who wrote a book about the year 320 with the title of Mathematical Collection: Pappus seems to have followed closely a work on isometric figures written almost half a millennium before by Zenodoro (about $180 \mathrm{BC}$ ), from which some fragments have come to us through later commentators. Among the propositions that appeared in the treatise of Zenodorus, there was one that affirmed that of all solid figures with the same surface, the sphere is the one with the maximum volume, but evidently only an incomplete justification was given "(Boyer, 1997).

Isoperimetric problems have an important place in the history of mathematics and in particular of optimization problems. Mention should be made of the legend that Princess Dido - the mythical figure of Phoenicia, considered the founder of Carthage - when she arrived in the ninth century BC to what is now Tunis, and wanted to buy land to settle with her people, only Was allowed to do so in such an extent that it could be enclosed by an immense rope. It is clear that the princess and the Phoenicians who accompanied her had to solve an isoperimetric problem: to determine the region of greatest possible area enclosed by the rope (the given perimeter). The intuitive solution is a circular region, whose circumference is of length equal to the one of the cord; however, the formal solution is not simple and was written after several centuries. The prominent German-Swiss mathematician Jacob Steiner (1796-1863) solved the problem by assuming the existence of the solution and considering three stages in his demonstration:

I. The curve must enclose a convex region.

II. Any straight line that divides the perimeter of the region by half, also divides the region into two parts that have the same area.

III. The half-circle of length P / 2 whose ends are on a given line, is the curve that encloses a region of maximum area, considering all the perimeter curves $\mathrm{P} / 2$ enclosing convex regions to one side of the line and with ends in it .

The differential calculus, with the significant contributions of Newton and Leibniz in the seventeenth century, systematically deals with the problems of maximum and minimum continuous functions of one and several variables. It is fair to remember the contributions with relevant (intuitive?) Ideas throughout history, of characters such as Eudoxus and Archimedes (before Christ), and of Cavalieri, Kepler, Torricelli and Fermat for the creation of 
the infinitesimal analysis.

We especially emphasize the contributions of Fermat (1601- 1665) for his ingenious methods to solve problems of maxima and minima, set forth in his memory Methodus and disquirendam maximam et minimam (Method to investigate maxima and minima).

In the year 1637 publishes his method based on the following rules:

I. Let $\mathrm{A}$ be a term related to the problem.

II. The maximum or minimum quantity is expressed in terms containing only powers of A;

III. A is replaced by $\mathrm{A}+\mathrm{E}$, and the maximum or minimum is then expressed in terms of powers of $\mathrm{A}$ and $\mathrm{E}$;

IV. The two expressions of the maximum or minimum become "adiguales", which means something like $<<$ as approximately as possible $>>$;

V. Common terms are deleted;

VI. All terms are divided by the same power of $\mathrm{E}$ so that at least one of the resulting terms does not contain $\mathrm{E}$;

VII. Terms that still contain E are ignored;

VIII.The remains become the same. (Andersen 1984: 38)

The contributions of Lagrange and Euler, outstanding scientists of the eighteenth century, allowed to treat the problems of optimization with several variables and restrictions of equality and to enter into optimization problems in which the optimizing element is neither a real number nor an $\mathrm{n}$ dimensional vector, But a function. We are referring to the calculation of variations and to the rigorous solution of problems such as the famous and historical "brachistochronous problem", according to which, one must find the plane curve along which a particle will slide only by influence of the Gravity and no friction, in a minimum time, from one point $\mathrm{P}$ to another $\mathrm{Q}$, considering these points in a vertical plane, $\mathrm{Q}$ lower than $\mathrm{P}$ but not both in a vertical line. Certainly, to find such a curve, is to find the function that defines it, and there were very ingenious solutions, with specific criteria for this problem, in response to the challenge posed by the one who proposed it - Johann Bernoulli in 1696 - to the mathematicians of that time; Among them, the solution of the same Johann Bernoulli, the one of Leibniz, the one of Jacques Bernoulli (brother of Johann) and the famous one of Newton. The calculation of variations is a theory that allows to solve rigorously this and many other problems of optimization, in which the optimizing element is a function, constituting a valuable contribution to other sciences.

The principles of Euler's variation in physics, rediscovered and diffused by the Irish mathematician W.R. Hamilton (1805 - 1865), have proven to be one of the most powerful tools in mechanics, optics and electrodynamics, with many applications to engineering. Recent advances in physics - relativity and quantum theory - are full of examples that reveal 
the power of calculus of variations (Courant \& Robbins 2002: 421-422). We thus have models of dynamic optimization, which in the twentieth century are used in models of economic theory. Moreover, with the contributions of Pontryagin, Hestenes, and other distinguished mathematicians, the theory of optimal control is consolidated in the twentieth century, which can be seen as a more general approach than that of calculating variations, since it introduces an additional variable to these Problems (the control variable) and considers between the constraints a differential equation that links the state variable with the control variable. The contributions of Bellman lead to the formulation of dynamic programming that includes the problems of optimal control in a family of control problems and pays special attention to the optimal value of the functional, unlike the calculation of variations and optimal control, which focus their attention on the optimal trajectories of the state and control variables. With this approach, problems of dynamic optimization, continuous variation and discrete variation are rigorously addressed.

Another great scenario of optimization problems is in linear programming, developed from the fourth decade of the twentieth century. The expression "linear programming" is already widespread, although it would be better to use the expression "linear optimization", to avoid confusion with the concept of programming closely linked to computer science. The developed methods allow to treat geometrically and computationally problems of optimal allocation of resources, and in the most diverse fields, such as economy, finance, transport and competitive games. In these problems, the function whose optimal value is sought and the functions that define the constraints of the variables are all linear. In a very short time linear programming has been applied in various fields and at the same time has developed and refined problem solving methods. It is worth mentioning that as early as 1826, Fourier discovered a method for manipulating linear inequalities, which is closely related to the solution of linear programming problems, as discussed in Williams (Courant and Robbins 2002). Next, we transcribe a paragraph of the article, which gives an idea of the close interrelationship, despite the great difference in time.

The valuable contributions of George Dantzig, L.V. Kantorovich and T.C. Koopmans (Nobel Prize in Economics in 1975 for his contributions to the theory of optimal allocation of resources) to the development of linear programming soon became also in nonlinear programming. The works of Kuhn and Tucker (1950) are historical, establishing necessary and sufficient conditions for the existence of optimal solutions to non-linear programming problems. Important relationships were found between duality in linear programming, von Neumann's game theory, and Kuhn-Tucker conditions. These conditions, which consider differentiable functions of $\mathrm{n}$ nonnegative variables and $\mathrm{m}$ constraints given by inequalities, can also be applied to linear programming problems and make evident the relationships between the results of duality theorems and sensitivity analyzes with Lagrange multipliers. A historical and mathematical analysis on the origins and evolution of linear and nonlinear programming makes Hoff Kjeldsen his doctoral thesis (1999).

Theoretical wealth in the treatment of non-linear programming problems and the multiple applications in various fields of science and technology have tremendously accelerated the development of optimization in general and is nowadays a very broad field of mathematics 
and with numerous Publications of high mathematical level on topics such as generalized monotony, generalized convexity, equilibrium problems - including multi objective optimization and game theory - variation inequalities, fixed points, Lagrangian augmentation, regularization techniques, discrete optimization, stochastic optimization, etc.

\section{The Problem of Optimization}

Referring to optimization problems in general, is to refer to a very broad scope of mathematics, and that is progressing more and more. In various fields of natural and social sciences including administration, optimization problems are found, formulated and solved. Linear programming problems are perhaps the most known or widespread, but there are problems of nonlinear programming, dynamic programming, discrete optimization, combinatorial optimization, concave optimization, stochastic optimization, and so on.

We will call optimization problem to any problem in which the fundamental objective is to obtain a maximum value or a minimum value of some variable (Williams 1986).

1. In the statement of an optimization problem, words or expressions are generally used as the maximum, the minimum, the most (or the most, the most), the least (or the least, least), the best, the worst (or the worst, the worst), at least the largest (or the largest), the smallest (or the smallest).

2. When referring to maximum or minimum values of a variable, we must specify that a set $\mathrm{C}$ is required in which the values of the variable are considered. In formal terms, a first level of optimization problem is the obtaining of a maximum element or a minimum element in a set $\mathrm{C}$ in which a complete preorder relationship has been defined; that is, a binary relationship, which is represented by $\leq$, reflexive and transitive, that can be established between any pair of elements of $\mathrm{C}$. The optimization problem is:

Given the ordered pair $(\mathrm{C} ; \leq)$, where $\mathrm{C}$ is a set in which the complete preorder relationship represented by $\leq$ is defined, determine $\mathrm{cm} \in \mathrm{C}$ such that $\forall \mathrm{c} \in \mathrm{C}, \mathrm{cm} \leq \mathrm{c}$ (c the minimum element)

\section{Is There an Optimizing Intuition?}

As a result of solving everyday optimization situations, we acquire an "optimizing" practice that, in some individuals, can become an actuarial intuition. It may even be considered that this accusative intuition is in itself the result of a process of optimization of the effort by the path of a social organism in its historical process. Indeed, by applying a recursive process to the first type of experiences, to ask ourselves about what can be the process that optimizes the effort represented by the optimizing rationalization, the answer to which we arrive is that the intuition that gives us the optimal solution is optimal in two senses, on the one hand, gives us the optimal solution and for The other saves the effort needed to find the solution.

We consider that there is reason to conjecture from the point of view of theoretical physics and mathematics that there is a comprehensive optimizing intuition of the primary type that helps us to understand optimization problems and that in some individuals there may be an 
optimizing intuition which leads to the solution of problems without the predominance of formal paths. This intuition is based on the Aristotelian epistemic cradle. In Table 1, the epistemological aspect is linked, as a synthesis, with the methodological outline of the optimization models.

Chart 1. Epistemology of the Optimization Models (Own elaboration based on a review of the bibliography).

\begin{tabular}{|c|c|c|}
\hline $\begin{array}{l}\text { Epistemic } \\
\text { cradle }\end{array}$ & Galilean & Aristotélian \\
\hline Current & Positivism & Critical theory \\
\hline $\begin{array}{l}\text { Predominant } \\
\text { part }\end{array}$ & $\begin{array}{l}\text { A cognoscenti subject who } \\
\text { considers that he can obtain } \\
\text { knowledge and influence } \\
\text { objective reality through } \\
\text { existing ideas }\end{array}$ & $\begin{array}{l}\text { It advocates the interaction between subject } \\
\text { and object in order to reach deeper knowledge } \\
\text { of the laws that govern reality, }\end{array}$ \\
\hline $\begin{array}{l}\text { Philosophical } \\
\text { perspective }\end{array}$ & \begin{tabular}{|l} 
Positivism. Emphasizes the \\
external, measurable and \\
quantifiable elements of \\
organizational events, which \\
can be represented by \\
statistical models
\end{tabular} & $\begin{array}{l}\text { Materialism. } \\
\text { The reality is changing and contradictory }\end{array}$ \\
\hline His method & \begin{tabular}{|l} 
Empiricism: \\
It is based on the quantitative \\
description of the facts \\
(statistics). Schematic, \\
uncritical and ahistorical \\
interpretation of the \\
organizational problem
\end{tabular} & $\begin{array}{l}\text { Holistic: } \\
\text { It emphasizes both the objective and the } \\
\text { subjective sense of social phenomena. } \\
\text { Intersubjective }\end{array}$ \\
\hline $\begin{array}{l}\text { Explanation } \\
\text { causality }\end{array}$ & $\begin{array}{l}\text { Galilean } \\
\text { Causal explanation }\end{array}$ & Aristotelian Explanation teleological \\
\hline Organization & $\begin{array}{l}\text { Positive Theory } \\
\text { Organizational }\end{array}$ & Critical Theory of the organization \\
\hline Theorists & \begin{tabular}{|l} 
Zenodoro (ca. 180 BC), \\
Pappus (340) \\
Apolonio (140) \\
Euler (1727) \\
Herón (First century AD) \\
Cauchy (1832) \\
Weierstrass (1852) \\
Dedekind (1872) \\
Taylor (1911) \\
Mayo (1923) \\
Weber (1888) \\
Merton (1975) \\
Crozier (1964) \\
Simón (1947) \\
Barnard (1938) \\
Parson (1937)
\end{tabular} & $\begin{array}{l}\text { Burrell (1979) } \\
\text { Morgan (1979) } \\
\text { Potter (1987) } \\
\text { Shotter (1993) } \\
\text { Gergen }(1985) \\
\text { Reed }(2003) \\
\text { Gibson }(1939) \\
\text { Maanen (2011) } \\
\text { Dilthey (1907) } \\
\text { Ranke (1834) } \\
\text { Windelband (1888) } \\
\text { Rickert (1924) } \\
\text { Quetelet (1835) }\end{array}$ \\
\hline
\end{tabular}




\begin{tabular}{|c|c|c|}
\hline & \begin{tabular}{|l} 
Stogdill (1974) \\
Popper (1929) \\
Hume (1739) \\
Match (1870) \\
Planck (1900) \\
Carnap 1922) \\
Parménides (550 BC) \\
Platón (450 BC) \\
Descartes (1622) \\
Malebranche (1683) \\
Spinoza (1670) \\
Leibnitz (1689) \\
Koopmans (1975) \\
Kjeldsen $(2004)$ \\
Bertalanffy (1968) \\
Dantzig (1975) \\
Kantorovich (1975) \\
Koopmans (1975)
\end{tabular} & \\
\hline Values & $\begin{array}{l}\text { Business } \\
\text { Efficiency } \\
\text { Production } \\
\text { Capital } \\
\text { Entrepreneurial ability } \\
\text { Capacity of administrator } \\
\text { and manager. } \\
\text { Capacity for visionary } \\
\text { institutional leadership. }\end{array}$ & $\begin{array}{l}\text { Human being } \\
\text { Emancipation } \\
\text { Actor } \\
\text { Meaning } \\
\text { Interpretation } \\
\text { Symbolisms }\end{array}$ \\
\hline $\begin{array}{l}\text { Optimization } \\
\text { Models }\end{array}$ & $\begin{array}{l}\text { Normative or Prescriptive } \\
\text { Model: } \\
\text { Linear programming theory } \\
\text { of games, capital budgets } \\
\text { and statistical decision } \\
\text { theory. } \\
\text { Model of Satisfaction, } \\
\text { Decision Behavior Model, } \\
\text { Programmed Decisions, } \\
\text { Economic Model, Model to } \\
\text { Optimize Decision Making, } \\
\text { Model of Limited } \\
\text { Rationality of }\end{array}$ & $\begin{array}{l}\text { Intuitive reflection optimization models, } \\
\text { Open Decision Model, Decision Model } \\
\text { Behavior, Non-Programmed Decisions, } \\
\text { Decision Making in Conditions of Certainty, } \\
\text { Decision Making in Risk Conditions, } \\
\text { Decision Making in Conditions of } \\
\text { Uncertainty, Simplified Reality Model, Model } \\
\text { of the Favorite Implicit, Intuitive Decision } \\
\text { Making, Scientific Method }\end{array}$ \\
\hline $\begin{array}{l}\text { Types } \\
\text { thinking }\end{array}$ & $\begin{array}{l}\text { Formal thinking for } \\
\text { optimization }\end{array}$ & Comprehensive optimizing intuition \\
\hline Principles & Nomothetic & Ideographic \\
\hline
\end{tabular}

\section{Final Reflection}

In the review, our answer is that there are reasons to suppose that yes and that this optimizing intuition has its origin, basically, in two types of daily experiences. The first type of 
experience has to do with the fact that in everyday life, we are often facing many optimization problems; For example, we look for the best way to go from place to place, we try to make the best choice when making a purchase in the market, we look for the best location when we go to a library, cinema or a theater, we try to teach the best possible, We choose the bride or groom, we try to choose the best proposal of government in an election. Obviously, in none of these cases do we use systematic processes, formalized mathematics, to find what we are proposing, because we face problems with the criteria that give us experience and intuition as we saw in the contributions of the early Greeks, although not necessarily Find the optimal solution. This type of situation entails an optimizing rationality that seeks to find the best solution to the situation. Experiences related to popular expressions such as "the law of minimum effort". The second type of experiences are related to the fact that we are subjects that we experience about ourselves how, over time, certain vital characteristics. For example, visual strength, physical strength, health, among others varies and goes through critical moments initiating bio-psycho-physical declines, maximum or minimum.

These two forms of life experiences are the ones that give us arguments to suppose that there is an "optimizing intuition" (of a primary type in Fischbein's terminology) that has two components: a comprehensive and an actuarial intuition. That is why we can understand comprehensive intuition as a metaphorical projection of certain experiences of everyday life; this projection allows us to have an understanding of what is a problem of optimization.

The importance of the need for such informed use of methods is revealed in the tendency to use parsimony and probabilistic methods without exploring the epistemological implications of such approaches in organizational and business reconstruction. Undoubtedly, interest in optimization methods is expanding; therefore, it is important that management scholars and organizational theory carefully consider the epistemological bases and relevance of the methods they use in selecting optimal topologies. We want to clarify that the continuation of this work is based on the development of the antecedents of the use of optimization models based on the intuitive reflection that do not require systematic formalities and those that they require

\section{Acknowledgments}

We thank the Program for Strengthening Educational Quality. Reprogramming 2016 (P / PFCE-201617MSU0017P-05 //) for the support granted for the publication of this article and that has to do withimproving the academic productivity of students and PTC of the FCAeI PE.

\section{References}

Andersen, K. (1984). Las Técnicas Del Cálculo, 1630-1660. Del Cálculo A La Teoría De Conjuntos, 1630-1910. Una Introducción Histórica.

Bernal, J. D. (1997). Historia Social De La Ciencia: La Ciencia En La Historia.

Boyer, E. L. F. (1997). Una Propuesta Para La Educación Superior Del Futuro. S.L.: S.N. 


\section{Macrothink}

International Journal of Human Resource Studies

ISSN 2162-3058

2017, Vol. 7, No. 3

378.73 B6.

Burrel, G. Y., \& Morgan, G. (2006). Sociological Paradigms And Organizational Analysis. Aldershot, Gower,

Cook, T. D., Reichardt, C. S., Solana, Y. G. (1986ª). Hacia Una Superación Del Enfrentamiento Entre Los Métodos Cualitativos Y Cuantitativos. Métodos Cualitativos Y Cuantitativos En Investigación Evaluativa. Madrid, España: Morata Madrid.

Cook, T. D., Reichardt, C. S., Solana, Y. G. (1986b). Los Métodos Cualitativos Una Experiencia Necesaria En La Investigación Evaluativa. Métodos Cualitativos Y Cuantitativos En Investigación Evaluativa. Madrid, España: Morata Madrid.

Courant, R. Y., \& Robbins, H. (2002). ¿Qué Son Las Matemáticas? Conceptos Y Métodos Fundamentales. S.L.: Fce.

Denzin, N. K. (1973). The Research Act: A Theoretical Introduction To Sociological Methods. S.L.: Transaction Publishers.

García, J. (1991). Lecciones Preliminares De Filosofía. México: Edesa.

Gergen, K. J. (1996). Realidades Y Relaciones: Aproximaciones A La Construcción Social. S.L.: Paidós.

Giddens, A. (1987). Las Nuevas Reglas Del Método Sociológico. Argentina: Amorrortu.

Grawitz, M. (1984). Métodos Y Técnicas De Las Ciencias Sociales. . S.L.:

Hessen, J., Gaos, J. Y Romero, F. (1970). Teoría Del Conocimiento. S.L.: Espasa-Calpe.

Ichijo, K., Krogh, G. Y Nonaka, T. (2000). Facilitar La Creación De Conocimiento. México: Oxford, México.

Kline, M. (1990). Mathematical Thought From Ancient To Modern Times: Volume 3. Usa: Oup Usa.

Kolakowski, L. Y., \& Ruiz-Ramón, G. (1979). La Filosofía Positivista: Ciencia Y Filosofía. S.L.: S.N.

Luengo-González, E. (1991). Problemas Metodológicos De La Sociología Contemporánea. México: Universidad Iberoamericana Ciudad De México.

Mardones, J. M. (1991). Filosofía De Las Ciencias Humanas Y Sociales: Materiales Para Una Fundamentación Científica. S.L.: Anthropos Editorial.

Maturana, H. R. Y Varela, F. J. (1990). El Árbol Del Conocimiento: Las Bases Biológicas Del Conocimiento Humano. Madrid, España: Debate Madrid.

Moles, A. A., Rohmer, E. Y Covarrubias, J. (1995). Las Ciencias De Lo Impreciso. Brasil: Civilização Brasileira Rio De Janeiro.

Nonaka, I., Takeuchi, H. Y., \& Kocka, M. H. (1999). La Organización Creadora De 


\section{Macrothink}

International Journal of Human Resource Studies

ISSN 2162-3058 2017, Vol. 7, No. 3

Conocimiento: Cómo Las Compañías Japonesas Crean La Dinámica De La Innovación. México: Oxford University Press México Df.

Oriol Anguera, A. Y Espinosa Hernández, P. (1994). Filosofía De La Ciencia. S.L.: México.

Perero, M. (1994). Historia E Historias De Matemáticas. . México: México, Mx: Edit. Iberoamericana.

Toffler, A. Y., \& Aparicio, R. (1990). El Cambio Del Poder: Powershift. S.L.: Plaza \& Janes. 303.4/T64pe.

Williams, H. P. (1986). Fourier'S Method Of Linear Programming And Its Dual. The American Mathematical Monthly, 93(9), 681-695. https://doi.org/10.2307/2322281

Wilson, T. P. Y Giddens, A. (1990). La Sociología Y El Método Matemático. Giddens, A., Y Turner, La Teoría Social Hoy. México: Consejo Nacional Para La Cultura Y Las Artes, Vol. 67.

\section{Copyright Disclaimer}

Copyright for this article is retained by the author(s), with first publication rights granted to the journal.

This is an open-access article distributed under the terms and conditions of the Creative Commons Attribution license (http://creativecommons.org/licenses/by/4.0/). 